\title{
Emerging Developmental Pathways to ADHD: Possible Path Markers in Early Infancy
}

\author{
Judith G. Auerbach, Naama Atzaba-Poria, Andrea Berger and Rivka Landau
}

Department of Behavioral Sciences, Ben-Gurion University, Beer-Sheva, Israel

\section{SUMMARY}

Sixty-six male infants participating in the Ben-Gurion Infant Development Study of familial risk for attention deficit hyperactivity disorder (ADHD) were assessed at 7 months of age using observational and mother report measures. Risk for ADHD was based on ADHD symptoms in the father. Infants whose fathers had seven or more symptoms formed the ADHD risk group; infants whose fathers had three or less symptoms formed the comparison group. The ADHD risk group significantly differed from the comparison group on measures of interest, anger, and activity level and showed less interest in block play and more anger reactivity but less directed anger in a barrier task. According to mother report, the ADHD risk group had higher levels of activity than the comparison group. Measures of neonatal immaturity and activity were related to behavior at 7 months. The findings suggest that possible developmental pathways to ADHD may be emerging in early infancy.

\section{KEYWORDS}

ADHD, familial risk, temperament, longitudinal, boys, infants

Reprint requests to: Judith Auerbach, Department of Behavioral Sciences, Ben-Gurion University, Beer Sheva, Israel 84 105; e-mail: judy@bgumail.bgu.ac.il

\section{INTRODUCTION}

One of the challenges of developmental psychopathology is to determine whether detectable pathways to developmental disorders are present in the first months or years of life. The present paper focuses on possible early path markers of vulnerability to a common developmental disorder, attention deficit hyperactivity disorder (ADHD). Although the literature on the early development of children with ADHD is surprisingly sparse, there is some indication that children who are genetically predisposed to the disorder or who eventually receive a diagnosis of ADHD already show certain vulnerabilities within the first year of life. Although not necessarily evidence of a specific pathway to the disorder, these vulnerabilities can increase the probability of such outcomes under certain environmental conditions.

ADHD is one of the most common disorders of childhood, having a prevalence of $3 \%$ to $5 \%$ (American Psychiatric Association [APA], 1994). The disorder is more common in boys than in girls, both in epidemiological and in clinical populations (APA, 1994; Breton et al., 1999; Szatmari, 1992). Evidence suggests that the disorder has both genetic and environmental underpinnings. First-degree relatives of children with ADHD are 7.6 times more likely to have the disorder than are relatives of normal children (Biederman et al., 1992). Furthermore, $60 \%$ of children having a parent with ADHD are likely to receive a childhood diagnosis of ADHD (Biederman et al., 1995). The high heritability estimates ( $75 \%$ to $90 \%$ ) for $\mathrm{ADHD}$ in 
twin studies support a strong genetic contribution (Goodman \& Stevenson, 1989; Levy et al., 1997), and recent evidence from molecular genetics further attests to a genetic basis of the disorder. A number of studies have found the dopamine D4 receptor gene (DRD4) (Faraone et al., 1999; LaHoste et al., 1996) and the dopamine transporter gene (DAT1) (Cook et al., 1995; Gill et al., 1997) to be associated with ADHD.

Family relationships, parent-child interaction, and family adversity are also associated with the development and severity of the disorder (Biederman et al., 1995; Cunningham \& Barkley, 1979; Jacobvitz \& Sroufe, 1987). Such conditions seem to be both antecedent to the disorder and a reaction to it, with the additional caveat that these conditions do not seem to be specific to the disorder itself but rather are risk factors for the development of childhood psychopathology (Campbell, 2000).

One of the first tasks in trying to construct potential pathways to ADHD is to link the deficits or difficulties seen in older children with ADHD to the behavioral repertoire characteristic of development in the first year of life. Two conceptual approaches are particularly appropriate for this task. One approach relates to temperamental variations in reactivity and regulation (Rothbart, 1989), with the behaviors defining ADHD falling at the extreme edge of a continuum of temperament traits seen throughout the general population (Taylor, 1999). Emotionality, activity, and attention/orienting are three reactivity domains of temperament with relevance to ADHD and individual differences in their expression can be seen in the first year of life (Buss \& Plomin, 1984; Goldsmith \& Campos, 1982; Rothbart, 1989; Thomas et al., 1968). The ability to regulate reactivity develops in the first years of life, and difficulties with rudimentary regulatory abilities can appear as early as the first weeks of life (Greenspan \& Weider, 1993). With regard to ADHD, certain evidence has suggested that difficulties with both reactivity and regulation characterize children with the disorder both before and after diagnosis, although accumulating evidence indicates that these difficulties do not necessarily form a specific pathway to ADHD (Anderson et al., 1994; Belsky et al., 1998; Campbell, 2000).

Difficulties with state organization and regulation have been found both in studies of ADHD risk samples and in general samples of infants with school-age outcome data. In our study of infants at familial risk for ADHD, the ADHD risk group tended to have more difficulties with neonatal state organization than did a comparison group (Auerbach et al., unpublished), that is they were more irritable, quicker to cry, and were less able to quiet themselves. A number of other studies found that negative emotionality, usually manifested as excessive crying, in the first year of life was predictive of attentional problems and hyper-activity at school age (Degangi et al., 1993; Rende, 1993; Wolke et al., 2002). Such difficulties are also predictive of other childhood psychopathologies, casting doubt on its uniqueness as a pathway or path marker to ADHD (Riese, 1987; Sanson et al., 1993).

From 6 months of age, anger is clearly differentiated as a negative emotion (Sroufe, 1995); it occurs as a reaction to interference with ongoing activity, such as restraining arm movements or blocking action toward a desired goal, such as reaching for an attractive toy (Barrett \& Campos, 1987; Buss \& Goldsmith, 1998). Difficulties with anger and its regulation are associated with ADHD from preschool through adulthood (Douglas \& Parry, 1994; Mash \& Johnson, 1982; Ramirez et al., 1997). These difficulties seem to be even more prominent for those with co-morbid externalizing disorders (Melnick \& Hinshaw, 2000).

As infants approach the second half of their first year, their attentional and manipulative skills improve and individual differences in object interest are clearly observable. The duration of looking and 
facial expressions of interest are indices of focused attention and seen most clearly in this period during the exploration and manipulation of toys (Ruff \& Rothbart, 1996). Stable individual differences in focused attention have been reported over a 2-week interval in the first year (Ruff \& Dubiner, 1987) and from age 12 to 24 months to 3.5 years for children who were either extremely low or extremely high in focused attention (Ruff \& Rothbart, 1996). Factors like novelty, the physical characteristics of the stimuli, and the rate of stimulus presentation and reinforcement are external determinants of focused attention (Cowan, 1988, Van der Meere, 2002). As attention becomes increasingly governed by higher order cognitive skills, it is less susceptible to external influence. One consequence of a deficit in self-regulation is that attentional skills, including focused attention, continue to be highly influenced by external factors (Van der Meere, 2002). Depending on the context, children with ADHD will show either difficulties with or normal levels of focused attention. As the task time continues and with no changes in stimulus or situational valence, children with ADHD have difficulty responding appropriately to the demands of the task.

Hyperactivity is a defining characteristic of ADHD and has high heritability (Goodman \& Stevenson, 1989). In the neonatal period, there are individual differences in activity level (Rothbart, 1989), and in our longitudinal study (Auerbach et al., unpublished), the ADHD risk group showed a marginally higher level of neonatal activity than the comparison group. These differences may become more obvious as the infants develop and the expression of activity becomes more varied. The stability of individual differences in activity level in the first year life is low for unselected samples of infants (Rothbart, 1989; Rothbart \& Bates, 1998) but has not yet been examined in a selected sample, as it will be in this paper. If in this type of sample individual differences are found to be stable and discriminative, then activity level in the first year of life can be an early appearing path marker of risk for ADHD. Its predictive ability from the second year on has been established for school-age activity level in normal and risk samples (Buss et al., 1980; Campbell et al., 1994).

The second conceptual approach to ADHD that is pertinent to early development is that of Kinsbourne (1973). He suggests that children with ADHD are suffering from a delay in neurological maturation resulting in behaviors considered deviant with reference to chronological age. Some support for this conceptualization comes from our study (Auerbach et al., unpublished). The ADHD risk group received less optimal scores than a comparison group on a behavioral factor, Neurodevelopmental Immaturity, which assessed the degree of tremulousness, startling, motor maturity, and activity level. In addition, Sroufe and his colleagues (Carlson et al., 1995; Jacobvitz \& Sroufe, 1987) found that a neonatal motor maturity cluster was predictive of hyperactivity in kindergarten. Hyperactive kinder-garteners scored less optimally on this cluster. By age 7, no differences between hyperactive and nonhyperactive children were seen on this cluster, but the motor maturity scores of the hyperactive children remained somewhat lower than the scores of non-hyperactive children. In addition to its manifestation in the domains of autonomic reactivity and motor maturity, plausibly, neurodevelopmental immaturity would have an impact on the attentional and cognitive-based behaviors seen in the second half year, such as interest in objects and goal-directed behavior.

In trying to delineate possible developmental pathways to ADHD, both conceptual approachesone based on temperamental variations in reactivity and in regulation and the other on developmental maturation-provide complimentary frameworks in which to begin the exploration. The focus of the present paper is on interest, anger, and activity, all of which show observable individual differences in the second half-year and have relevance to ADHD. Consequently, one aim of the present 
study was to examine whether the expression of these traits is related to familial risk for ADHD. Based on our neonatal findings and the observation that high levels of activity are characteristic of children with ADHD, we hypothesized that the ADHD risk group would show higher levels of activity at 7 months of age than would a comparison group. A directional hypothesis regarding interest is less clear cut. Because novelty affects focused attention, which is one index of interest, group differences in an unfamiliar task may not occur. On the other hand, a hypothesis based on neurodevelopmental immaturity would predict that the ADHD risk group would show lower levels of interest because of such immaturity. With respect to anger, this behavior can be categorized either as reactive to a frustrating situation or as directed against the object of frustration. The latter is to some extent a cognitive-based behavior because the goal of directed anger is to remove the object of frustration; therefore, the infant has to understand what is blocking his behavior and direct his behavior toward removing the blocking object. The neurodevelopmental immaturity hypothesis led to the prediction that infants in the ADHD risk group would show less goal-directed anger than the comparison group. As for anger reactivity, both conceptual approaches would predict that infants in the ADHD risk group would show higher levels of anger reactivity than the comparison group. This prediction is also in line with our neonatal findings and with other research on infant negative emotionality and its prediction of later attentional difficulties and hyperactivity.

A second aim of the study was to explore whether neonatal behavior, particularly those behaviors showing group differences, was related to behavior at 7 months. If so, this relation would suggest the emergence of a possible developmental pathway that might eventuate in ADHD, given certain environmental conditions. In the neonatal period, behavior was assessed both behaviorally and by mother report (Auerbach et al., unpublished). The behavioral factors of State Organization Difficulties and Neurodevelopmental Immaturity showed group differences, whereas an item measuring activity level showed marginal differences. An additional factor, Stimulus Responsivity, also had discriminatory value but was limited to a subgroup within the ADHD risk group. Infants whose fathers were classified as showing symptoms primarily of hyperactivity/ impulsivity scored higher on this factor than infants in the comparison group or than infants whose fathers showed primarily inattentive symptoms. In other words, the Hyperactive/ Impulsive risk subgroup showed more responsivity to visual and visual-auditory stimulation than did the other groups. Mother reports of interest, anger, and activity showed no group differences neonatally. For the current paper, we examined the relation among the three neonatal behavioral factors and the activity level item, the neonatal mother reports of interest, anger, and activity, and interest, anger, and activity as observed and reported at 7 months. Because data collection is ongoing, the analyses were based on infants for whom both neonatal and 7-month data were available.

\section{EXPERIMENTAL}

\section{Sample}

The sample for this paper consisted of 7-monthold male infants $(n=66)$ who had been examined neonatally in the first stage of the Ben-Gurion Infant Developmental Study (BIDS). The sample was limited to boys because of the higher prevalence (3:1 to 9:1) of ADHD among boys (American Psychiatric Association, 1994; Danckaerts \& Taylor, 1995). All children were from two-parent families. The parents were native-born Israelis or immigrants who had studied in Israel and spoke 
Hebrew. Recruitment occurred in the Maternity Ward of the Soroka Medical Center in Beer Sheva. At the hospital, the fathers were requested to complete a questionnaire assessing current ADHD symptomatology (Auerbach et al., unpublished). Entry into the study was based on the number of positive responses (yes-no format) fathers made to the ADHD items. The criterion for recruitment into the ADHD risk group was a score of $\geq 7$, and recruitment into the comparison group was based on a score of $\leq 3$. The respective mean levels of symptoms for the ADHD risk group and the comparison group were $9.73(\mathrm{SD}=2.34)$ and 1.47 $(\mathrm{SD}=1.24)$. A cutoff score of at least seven symptoms for the risk group was decided upon because it was high enough above the mean to indicate moderate symptomatology and low enough to ensure a large enough risk sample to follow longitudinally. The comparison group was matched with the ADHD risk group on parental education, age, and ethnicity. To date, data on 66 infants, 46 in the ADHD risk group and 24 in the comparison group, have been obtained from two time points: neonatal period $(M=30.45$ days, $S D=11.06)$ and at the age of 7 months $(M=7.5$ months, $S D=1.27)$.

\section{Measures}

Neonatal Behavioral Assessment Scale (NBAS). (Brazelton \& Nugent, 1995). The NBAS assesses the behavioral repertoire of neonates from birth to 2 months of age. The NBAS consists of items measuring the physiological, motoric, state, and interactive organization of the neonate. A Principal Components Analysis (PCA) with Varimax rotation was used to reduce the individual behavioral items to a smaller number of components. Based on previous factor analytic studies of the NBAS (Jacobson et al., 1984; Sameroff, 1978), solutions with five and six factors were examined. A fivefactor extraction yielded the most interpretable solution and explained $56.88 \%$ of the variance. A complete description of the PCA appears in
Auerbach et al. (unpublished). Only those factors, Stimulus Responsivity, State Organization Difficulties, and Neurodevelopmental Immaturity, showing group differences are included in the present paper. An NBAS item measuring the activity level is also included in the present paper because of its pertinence to ADHD risk and its marginal discriminative ability in the neonatal assessment.

Infant Behavior Questionnaire. The Infant Behavior Questionnaire (IBQ, Rothbart, 1981) is a 94-item parent questionnaire assessing infant temperament in the first year of life. The IBQ consists of six behavioral scales: Distress to Limitations (Anger), Distress to Sudden or Novel Stimuli (Fear), Activity Level, Duration of Orienting (Interest), Smiling and Laughter (Pleasure), and Soothability. Caregivers are asked to report on a 7-point scale the relative frequency of occurrence of specified infant reactions in concrete situations across the previous 2 weeks or the previous week for infants younger than 3 months of age. The IBQ scores reflect the ease of elicitation of a given reaction and the intensity of that reaction. Both the stability and validity of the IBQ have been documented (Rothbart, 1986). The IBQ was translated into Hebrew and used in previous studies (Auerbach et al., 1999, 2001).

The scales relevant for the present paper are those measuring Interest (Duration of Orienting), Anger (Distress to Limitations), and Activity Level. In the neonatal period, ${ }^{1}$ negative emotions are not clearly differentiated, therefore the Distress to Limitations scale and Distress to Sudden or Novel Stimuli scale were combined to form a Negative Emotionality scale (Cronbach alpha $=.79$ ). The respective Cronbach alphas for the neonatal Interest scale and the Activity Level scale were .79 and .78 . At 7 months of age, the Cronbach alphas were .82

\footnotetext{
${ }^{1}$ As certain IBQ items are not appropriate in the first months of life, only items that at least $50 \%$ of the mothers reported were used to form the scales.
} 
for Interest (Duration of Orienting), .76 for Anger (Distress to Limitations), and .76 for Activity Level.

Laboratory Temperament Assessment Battery (Lab-TAB-Prelocomotor version). The Lab-TAB (Goldsmith \& Rothbart, 1994) is an observational measure of temperament consisting of a series of behavioral episodes designed to tap a variety of temperament domains. Three episodes measuring the temperamental domains of interest, anger, and activity are included in the present paper. Task orientation/interest was measured using the Block Play episode. An attractive toy placed behind the Barrier episode was used to examine the negative emotion of anger. Finally, activity was observed in the Prone and Supine placement episode. All episodes were videotaped. The videotapes were coded by coders who were blind to the group status of the infants. For latency measures, percent agreement was calculated and kappa coefficients were used for all other behaviors.

Block Play (Interest/Persistence). This episode was designed to elicit sustained attention as measured by visual interest and the manipulation of blocks. The infant was seated at a table with the mother seated at the right side of the table approximately 1 meter from the infant. The mother was asked to remain as uninvolved as possible. The experimenter set four brightly colored blocks of different shapes in front of the child and left the room, returning after 3 minutes.

The 3-minute observational episode was divided into 1-minute intervals, each of which was subdivided into 10-second intervals. The infant variables coded in this episode included duration of looking, manipulation of toys, and intensity of facial expression interest. Both duration of looking and manipulation of stimuli were rated on a 4-point scale ranging from (0) 'Does not look/ manipulate at blocks at all' to (4) 'Child spends 9-10 seconds looking/manipulating the blocks'. Intensity of facial interest was coded on a 3-point scale ranging from (0) 'no facial region shows codable interest/infant is not looking at the blocks', to (2) a definite facial indication of interest. The kappa coefficients, a measure of inter-rater reliability, ranged from .69 for intensity of facial interest to .89 for duration of looking. In addition, latency to first look away was coded. Inter-rater agreement within 1 second was $100 \%$. A composite variable Interest was created by summing the standardized scores of duration of look, duration of manipulation and facial expression. Intercorrelations among these variables ranged from $r=.59$ to $r=.84$.

Attractive toy placed behina barrier episode (Anger). This episode is designed to elicit frustration and anger by placing a toy with which the child has been playing behind a barrier. The infant was seated at the table with the mother and the experimenter was seated approximately 1 meter from the child, each at opposite sides of the table. The experimenter presented to the child the attractive toy, a colorful ball that makes rattling sound, demonstrated how it works, and placed it in front of the child. The infant was allowed to play with the toy for 15 seconds. Then the experimenter put a glass barrier in front of the child and within his reach, moved the toy, and placed it behind the barrier. The toy was left there for another 30 seconds and then was given back to the child. This procedure was repeated three times.

Each trial was divided into 5-second epochs for a total of 30 seconds. In each epoch, the variables coded included the latency-to-anger response, push against barrier, and banging table. Furthermore, there were three ratings of intensity:

1. intensity of force ranging from (0) 'no movement toward barrier' to (4) 'very high intensity movement throughout the epoch';

2 . intensity of anger facial expression ranging from (0) 'no facial region shows codable movement' to (3) 'an appearance change occurs in all three facial regions, or impression of strong anger; and

3. intensity of negative (distress) vocalization ranging from (0) 'no distress' to (5) 'full intensity cry/scream'. 
The kappa coefficients ranged from .76 for distress vocalization to .92 for push against barrier. For latency to anger, inter-rater agreement was 100 percent within $1 \mathrm{~s}$.

Based on the intercorrelations among the variables, two composites were created. The first composite variable Anger Reactivity was created by the summation of the standardized scores of intensity of facial expression, negative vocalization, and banging table. Intercorrelations ranged from $r=.62$ to $r=.73$. The second composite variable Directed Anger was the sum of the standardized scores of push against barrier and the intensity of force. The two variables were highly correlated $(r=.87)$.

Prone and Supine placement episode (Activity). This episode measures the infant's activity level in the laboratory during a situation in which no overt activity-eliciting stimuli were present. Infants were placed in the supine and prone positions and their vigor of movements was measured. Specifically, infants were placed on the mat in a supine position when the mother and experimenter stood behind the mat, approximately $1 \mathrm{~m}$ eter away. After 30 seconds, the experimenter lifted the child and placed him in a prone position for another 30 seconds. The 30 -second trials were further divided into three 10 -second epochs. The vigor of movement was coded for each epoch on a scale ranging from (0) extremely low vigor: "lying on the quilt with very little movement except looking around" to (4) extremely high vigor: "thrashing of arms and legs that leads to whole-body movements". The kappa coefficient for this variable was .93 .

\section{Procedure}

Neonatal behavior was evaluated during a home visit. During this visit, the mothers completed the IBQ, and the NBAS was administered by graduate students in developmental psychology who were trained to a reliability criterion of at least $92 \%$ by JA. At 7 months, the families came to the Developmental Psychology Laboratory located in the Department of Behavioral Sciences, BenGurion University. Because of the length of the observation, two visits to the laboratory were necessary. At the laboratory, the mothers again completed the IBQ, the Lab-TAB procedure was conducted, and all episodes were filmed. Observational data were not available for all infants because of an inability to schedule a second visit to the laboratory or because of equipment failure. Infants received a small gift for their participation. In both assessments, the examiners were blind as to group placement of the families. Parents gave written informed consent at both assessment periods.

\section{RESULTS}

\section{Group differences}

The descriptive statistics and group comparisons for the Lab-TAB tasks and the IBQ scales are presented in Table 1 . Two multivariate analyses were preformed: one for the Lab-TAB composite variable plus Vigor of Movement and one for the IBQ scales. For the Block and Barrier tasks, composite variables were examined first and if significant, the variables composing them were analyzed. Cohen's $d$ was calculated to determine effect size. A $d=.20$ is considered small, a $d=.50$ is medium, and a $d=.80$ is large.

Multivariate analysis of the composites, Interest, Anger Reactivity, Directed Anger, and Vigor of Movements was significant (Wilk's Lamda $=.74$, $\mathrm{F}(4,34)=3.04, \mathrm{p}=.03$ ). For the three IBQ scales, Wilk's Lamda was .93 $(F[3,55]=1.34, p=.27)$.

In the Block task, the ADHD risk group obtained a significantly lower score on the composite variable Interest than did the comparison group. At the level of individual variables, the risk group manipulated the toys significantly less and showed significantly less facial interest. No group differences were found for the IBQ Interest scale. 
TABLE 1

Comparison of groups on Lab-TAB tasks and IBQ scales

\begin{tabular}{|c|c|c|c|c|c|c|}
\hline Measure & \multicolumn{4}{|c|}{ Group } & & \\
\hline Lab-TAB & \multicolumn{2}{|c|}{$\begin{array}{c}\text { ADHD risk } \\
\mathrm{N}=31\end{array}$} & \multicolumn{2}{|c|}{$\begin{array}{c}\text { Comparison } \\
N=21\end{array}$} & & \\
\hline Blocks & $M$ & SD & $M$ & SD & $t$ & $\begin{array}{c}\text { Effect size } \\
\text { (d) }\end{array}$ \\
\hline Latency to look away & 26.50 & 23.50 & 28.20 & 36.16 & .20 & .06 \\
\hline Interest & -.11 & .99 & .29 & .53 & $1.87^{\star}$ & .50 \\
\hline Facial expression & 2.99 & 1.53 & 3.63 & .74 & $1.99^{*}$ & .54 \\
\hline $\begin{array}{l}\text { Duration of } \\
\text { manipulation }\end{array}$ & 1.88 & .89 & 2.31 & .51 & $2.20^{*}$ & .59 \\
\hline Duration of look & 2.34 & .68 & 2.48 & .54 & .80 & .23 \\
\hline Barrier & \multicolumn{2}{|c|}{$N=35$} & \multicolumn{2}{|c|}{$N=21$} & & \\
\hline $\begin{array}{l}\text { Latency to anger } \\
\text { response }\end{array}$ & 132.43 & 62.21 & 153.79 & 44.27 & 1.50 & .40 \\
\hline Anger reactivity & .14 & .65 & -.12 & .34 & $1.99^{*}$ & .50 \\
\hline Facial expression & .27 & .40 & .10 & .22 & $2.00^{*}$ & .53 \\
\hline Negative vocalization & .39 & .54 & .20 & .28 & $1.72^{\dagger}$ & .44 \\
\hline Bang table & .06 & .10 & .03 & .05 & 1.55 & .38 \\
\hline Directed anger & -.18 & .86 & .30 & .55 & $2.54^{* \star}$ & .66 \\
\hline Push & .44 & .29 & .60 & .24 & $2.11^{*}$ & .60 \\
\hline Force of push & .85 & .66 & 1.16 & .56 & $1.84^{\dagger}$ & .51 \\
\hline $\begin{array}{l}\text { Prone \& supine } \\
\text { Placement }\end{array}$ & \multicolumn{2}{|c|}{$N=34$} & \multicolumn{2}{|c|}{$N=25$} & & \\
\hline Vigor of movement & -.001 & 1.10 & .08 & .85 & .29 & .08 \\
\hline \multicolumn{7}{|l|}{$\mathrm{IBQ}^{\mathrm{a}}$} \\
\hline Interest & 4.72 & 1.06 & 4.80 & 1.03 & .28 & .08 \\
\hline Anger & 3.68 & .74 & 3.63 & .75 & .26 & .08 \\
\hline Activity level & 4.50 & .86 & 4.11 & .58 & $2.08^{*}$ & .53 \\
\hline
\end{tabular}

${ }^{a} \mathrm{Ns}$ for IBQ range from 38-42 for ADHD risk group and 22-24 for comparison group.

Note: Composite scores are $\mathrm{z}$ scores; Lab-TAB items scores and IBQ scales are raw scores.

${ }^{\dagger} \mathrm{p}<.10^{*} \mathrm{p}<.05 * * \mathrm{p}<01$ 
TABLE 2

Correlations between neonatal and 7-month measures

\begin{tabular}{|c|c|c|c|c|c|c|c|}
\hline \multirow[b]{3}{*}{ Neonatal } & \multicolumn{7}{|c|}{7 months } \\
\hline & \multicolumn{4}{|c|}{ Lab-TAB } & \multicolumn{3}{|c|}{$\mathrm{IBQ}$} \\
\hline & Interest & $\begin{array}{c}\text { Anger } \\
\text { Reactivity }\end{array}$ & $\begin{array}{c}\text { Directed } \\
\text { Anger }\end{array}$ & $\begin{array}{l}\text { Vigor of } \\
\text { Movements }\end{array}$ & Interest & Anger & $\begin{array}{l}\text { Activity } \\
\text { Level }\end{array}$ \\
\hline \multicolumn{8}{|l|}{ NBAS } \\
\hline $\begin{array}{l}\text { Neurodevelopmental } \\
\text { Immaturity }\end{array}$ & $-.39^{\star \star}$ & .02 & $-.33^{*}$ & -.18 & .02 & .05 & .06 \\
\hline State Regulation Difficulties & -.12 & -.12 & -.09 & .15 & -.02 & .10 & .01 \\
\hline Stimulus Responsivity & .21 & .20 & .14 & .14 & -.03 & .11 & -.06 \\
\hline Activity Level & -.04 & .16 & -.01 & -.05 & .08 & .10 & $.28^{*}$ \\
\hline \multicolumn{8}{|l|}{ IBQ } \\
\hline Interest & -.10 & -.16 & .20 & -.06 & $.27^{\star}$ & -.18 & .02 \\
\hline Negative Emotionality & -.19 & .21 & $-.24 \dagger$ & -.10 & .04 & $.33^{* *}$ & .11 \\
\hline Activity Level & -.21 & .20 & $-.32^{*}$ & .03 & .15 & $.26^{*}$ & $.29^{*}$ \\
\hline
\end{tabular}

${ }^{\dagger} \mathrm{p}<.10 * \mathrm{p}<.05 * * \mathrm{p}<.01$

In the Barrier task, the ADHD risk group was significantly different from the comparison group on the composite variables Anger Reactivity and Directed Anger. The ADHD risk group scored higher on Anger Reactivity and lower on Directed Anger than the comparison group. At the level of the composites' individual variables, the ADHD risk group showed significantly more anger facial expression and a tendency for more negative vocalizations than the comparison group but made significantly fewer directed movements to remove the barrier, and when they did push against the barrier, there was a tendency for a less forceful push as compared with that of the comparison group. No group differences in anger were reported by mothers on the IBQ.
In the Activity observation, no differences were found between the groups in Vigor of Movements. In contrast, there was a significant difference between the groups in activity level when based on the IBQ Activity Level scale. According to the mother report, the ADHD risk group was significantly more active than the comparison group.

\section{Correlations between neonatal and 7-month measures}

The results of the correlational analyses are presented in Table 2. For these analyses, the groups were combined to increase the power of the analysis. 
Interest. A significant negative correlation was found between 7-month Interest and neonatal Neurodevelopmental Immaturity, that is, infants showing less interest in the block task were characterized as showing more immaturity neonatally. In addition, neonatal IBQ Interest and 7-month IBQ Interest were significantly correlated. Mothers who rated their infants as high in orienting and attending to environmental stimuli as neonates continued to so rate them at 7-months.

Anger. Anger Reactivity was not associated with antecedent or concurrent measures. In contrast, Directed Anger was significantly negatively correlated with NBAS Neurodevelopmental Immaturity and neonatal NBAS Activity Level. Infants showing less directed anger at 7 months were characterized as showing more immaturity and higher activity levels as neonates. Also, a borderline association was found between Directed Anger and neonatal IBQ Negative Emotionality. Infants who reacted to the barrier by pushing it forcefully were reported as showing less emotional distress in the neonatal period.

Anger as measured at 7 months of age by mother report (IBQ) was positively related to neonatal IBQ Negative Emotionality, and IBQ Activity Level. Mothers who perceived their neonates as distressed and active rated them angrier at age 7 months.

Activity. The 7-month IBQ Activity Level was significantly positively correlated with neonatal NBAS Activity Level and IBQ Activity Level; the more active the neonate, the more active he was at age 7 months according to mother report.

In addition to cross-age correlations, two significant correlations among the 7-month measures were found. Interest was significantly correlated with Directed Anger $(r=.48, p<.001)$, such that infants who expressed interest in the blocks through manipulation and facial expression also showed more anger directed toward the barrier. Vigor of movements at 7 months of age was significantly positively correlated with 7- month IBQ Anger $(r=.35, p<.05)$. Infants who showed more vigorous movements in the laboratory were reported by their mothers to exhibit more anger.

\section{DISCUSSION}

Interest, anger, and activity were found to differentiate between a group of infants at familial risk for $\mathrm{ADHD}$ and a comparison group in ways that seem to reflect risk-related temperamental variations and neurodevelopmental immaturity. Some linkage between neonatal vulnerability indices - specifically neurodevelopmental immaturity and activity level-and 7-month indices was found.

The ADHD risk group showed significantly less interest in the block task than the comparison group. These differences were not due to differences in attending visually to the blocks. The brightly colored, multi-shaped blocks seemed to stimulate all the infants to attend to them. It could be that the physical characteristics of the blocks were strong enough to maintain the infants' visual attention to them regardless of risk status. It is also possible that our 4point measure of attention was too crude to detect differences between the groups. What did differentiate between the groups was facial interest and duration of manipulation. Although manipulation could be considered an index of activity level, the observation that it was combined with facial interest supports a cognitive, maturational interpretation. Jeannerod (1994) suggests that action on objects is a higher level goal-directed skill than is goal-directed looking, therefore, the observation that the ADHD risk group showed less manipulation of the blocks may be indicative of what Kinsbourne (1973) calls neurodevelopmental immaturity. $\mathrm{T}$ his possibility is supported by the significant negative correlation between block Interest and NBAS Neurodevelopmental Immaturity.

The ADHD risk group showed more Anger Reactivity than the comparison group but the risk 
group did not direct their anger toward the source of the frustration-the barrier. Directed Anger seems to have a cognitive component to it because anger becomes directed only when the infant can understand that his goal-directed acts are being blocked. Additional support for a cognitive component to Directed Anger comes from its significant positive correlation with block Interest. Kinsbourne's neurodevelopmental immaturity hypothesis again seems a plausible explanation for these differences, especially because Directed Anger, like Interest, was negatively associated with NBAS Neurodevelopmental Immaturity.

Although significant differences were found in Anger Reactivity and Directed Anger between the two groups in the direction predicted, the degree of anger in both groups was minimal. The Barrier task may not be especially effective in eliciting anger at this age because of the cognitive demands of the task. Seven-month old infants are just beginning to engage in goal-directed intentional behavior and therefore, the barrier task may not elicit as wide a range of anger as might a situation involving physical restraint. Even though the task did not evoke stronger anger, it is of note that the differences in anger reactivity are similar to our neonatal finding in that the ADHD risk group at both assessment points showed stronger negative emotional/anger reactivity than the comparison group. These findings are compatible with a temperamental variations approach to ADHD (Taylor, 1999), which would predict difficulties with reactivity in an at-risk population. Moreover, in prospective studies of children who eventually develop ADHD symptoms (Degangi, et al., 1993; Rende, 1993; Wolke et al., 2002), negative emotionality and anger have been linked to ADHD, both in retrospective accounts of children with ADHD (Weiss \& Hechtman, 1993) and in self-reports measures of adults with ADHD (Ramirez et al., 1997). Although not a specific marker of ADHD given its association with other types of psychopathology, negative emotionality may increase the probability of such an outcome when combined with a parental history of the disorder (Campbell, 2000) and a childrearing environment characterized by overstimulating, intrusive, and restrictive parenting (Jacobvitz \& Sroufe, 1987; Morrell \& Murray, 2003; Olson et al., 1990).

Studies of older children have found that the activity level is predictive of later activity level and of attentional functioning (Buss et al., 1980; Campbell et al., 1994; Ruff \& Lawson, 1990). Our results support the possibility that the discriminative value of activity level and its predictive ability can begin in the first year of life, at least for selected samples of infants. The ADHD risk group was reported by their mothers to be significantly more active than the comparison group. This difference was limited to mother report, perhaps because the laboratory observation was too brief (60 seconds) and the measure of activity too limited (one variable) to tap adequately individual differences in activity. The possibility that activity level may be an early path marker to ADHD is strengthened by the finding that neonatally, the ADHD risk group was marginally more active than the comparison group. The difference at age 7 months was stronger and significantly related to both neonatal measures of activity level. Our finding of stability in activity level from the first month of life to the second half of the first year is in contrast to other studies failing to find stability (Rothbart, 1989; Rothbart \& Bates, 1998). That our sample included infants at risk of a disorder characterized by high levels of activity probably contributed to this stability.

There are several limitations to the findings presented here. One, the findings are based on a partial sample of an ongoing longitudinal study. Second, our statistical approach increased the possibility of a Type I error. A more conservative approach would be to set the alpha levels higher but, as this is the first at-risk study of ADHD, it seemed appropriate to err on the side of potential 
false positives. In addition, the measures reported here represent only a subset of the observational and questionnaire data that have been collected. A more comprehensive picture of the functioning of the infants will be obtained when the coding of all the observational measures has been completed, including observations of mother-infant and fatherinfant interaction. In addition, group assignment was based on the fathers' responses to an ADHD questionnaire and not on a psychiatry interview or independent confirmation of ADHD. Even so, the fathers with high scores $(7+)$ can be considered higher than those of the general population on a continuum of traits associated with ADHD. Lastly, our findings can not be generalized to girls at risk for ADHD because the sample was limited to boys, due to the higher prevalence of ADHD in boys. In high risk longitudinal studies, it is important to optimize the probability that the incidence of the disorder will be high enough to allow for an adequate exploration of its developmental pathways. For this reason, we chose to study sons born to fathers with high ADHD symptomatology.

The present paper has focused on three areas of infant behavior that may be possible path markers to ADHD. Nevertheless, every child grows up within a context (Bronfenbrenner, 1977), and without reference to that context, any attempt to delineate pathways to complex childhood disorders, such as ADHD, would be incomplete. It is surprising how little attention has been paid to possible environmental contributions to the development of the disorder. From research on the developmental outcome of hard-to-manage children (Campbell, 2002), some of whom developed ADHD, clearly the environment plays a complex mediating and moderating role in determining the outcome. The predictive power of childrearing and parent-child factors to later attentional difficulties and hyperactivity/impulsivity has been amply demonstrated by Jacobvitz \& Sroufe, (1987) and by Olson and her colleagues $(1990,2002)$ in two samples that were not selected for genetic risk to ADHD. In their studies, the predictive power of a few early infant characteristics, such as neonatal immaturity and difficult temperament, lost their effect, whereas the role of parent-child relationship factors became increasingly important. Even so, a question remains as to the nature and extent of the contribution of the caretaking environment to the development of ADHD when children are genetically predisposed to the disorder-one of the questions that the Ben-Gurion Infant Development Study is designed to answer.

\section{ACKNOWLEDGMENTS}

We wish to thank our graduate students Nira Cypin and Adi Friedman who collected and were responsible for coding the 7-month data on which the analyses are based. We also wish to thank the families who participate in the project. The project is funded by a grant from the Israel Science Foundation founded by the Israel Academy of Sciences and Humanities.

\section{REFERENCES}

American Psychiatric Association. 1994. Diagnostic and Statistical Manual of Mental Disorders. 4th edition. Washington, DC, USA: APA.

Anderson C, Hinshaw S, Simmel C. 1994. Motherchild interactions in ADHD and comparison boys: Relationships with overt and covert externalizing behavior. J Abnorm Child Psychol 22: 247-265.

Auerbach J, Benjamin J, Faroy M, Kahana M, Geller V, Ebstein RB. 2001. DRD4 related to infant attention and information processing: A developmental link to ADHD? Psychiatr Genet 11: 31-36.

Auerbach JG, Landau R, Berger A, Arbelle S, Faroy $M$, Karplus M. Unpublished. Neonatal behavior of infants at familial risk for ADHD.

Auerbach J, Geller V, Letzer S, Shinwell R, Belmaker $\mathrm{R}$, Levine J, et al. 1999. Dopamine D4 receptor (D4DR) and serotonin transporter promoter (5- 
HTTLPR) polymorphisms in the determination of temperament in two month old infants. Molecular Psychiatry 4: 369-374.

Barrett K, Campos J. 1987. Perspectives on emotional development. II: A functionalist approach to emotions. In: Osofsky J, ed, Handbook of Infant Development, Vol. 2, New York, NY, USA: Wiley; 555-577.

Belsky J, Kuang-Hua H, Crinc K. 1998. Mothering, fathering, and infant negativity as antecedents of boys' externalizing problems and inhibition at age 3 years: Differential susceptibility to rearing experience? Dev Psychopathol 10: 301-319.

Biederman J, Faraone SV, Keenan K, Benjamin J, Krifcher B, Moore C, et al. 1992. Further evidence for family-genetic risk factors in attention deficit hyperactivity disorder: Patterns of co-morbidity in probands and relatives in psychiatrically and pediatrically referred samples. Arch Gen Psychiatry 49: 728-738.

Biederman J, Faraone S V, Mick E, Spencer T, Wilens $T$, Kiely $\mathrm{K}$, et al. 1995. High risk for attention deficit hyperactivity disorder among children of parents with childhood onset of the disorder: A pilot study. Am J Psychiatry 152: 431-435.

Brazelton TB., Nugent JK. 1995. Neonatal Behavioral Assessment Scale. Cambridge, UK: Cambridge University Press.

Breton J, Bergeron L, Valla J P, Berthiaume C, Gaudet N, Lambert J, et al. 1999. Quebec Children Mental Health Survey: Prevalence of DSM-III mental health disorders. J Child Psychol Psychiatry 40: 375-384.

Bronfenbrenner U. 1977. Toward an ecology of human development. Am Psychol 32: 513-531.

Buss AH, Plomin R. 1984. Temperament: Early Developing Personality Traits. Hillsdale, New Jersey, USA: Erlbaum.

Buss DM, Block JH, Block, J. 1980. Preschool activity level: Personality correlates and developmental implications. Child Development 51: 401-408.

Buss KA, Goldsmith HH. 1998. Fear and anger regulation in infancy: Effects on the temporal dynamics of affective expression. Child Dev 69: 359-374.

Campbell SB. 2000. Attention-deficit hyperactivity disorder: A developmental review. In: Sameroff AJ, Lewis M, Miller SM, ed, Handbook of Developmental Psychopathology. $2^{\text {nd }}$ edition. New York, NY, USA: Kluwer Academic/Plenum
Press; 383-401.

Campbell SB. 2002. Behavior Problems in Preschool Children. $2^{\text {nd }}$ edition. New York, NY, USA: The Guilford Press.

Campbell SB, Pierce EW, March CL, Ewing LJ, Szumowski EK. 1994. Hard-to-manage preschool boys: Symptomatic behavior across contexts and time. Child Dev 65: 836-851.

Carlson, EA, Jacobvitz DJ, Sroufe LA. 1995. A developmental investigation of inattentiveness and hyperactivity. Child Dev 66: 37-54.

Cook EH, Stein MA, Krasowski MD, Cox NJ, Olkon DM, Kieffer JE, et al. 1995. Association of attention deficit disorder and the dopamine transporter gene. Am J Human Genet 56: 993-998.

Cowan, N. 1988. Evolving conceptions of memory storage, selective attention, and their mutual constraints within the human informationprocessing system. Psychol Bull 104: 163-191.

Cunningham CE, Barkley RA. 1979. The interactions of hyperactive and normal children with their mothers during free play and structured tasks. Child Dev 50: 217-224.

Danckaerts M, Taylor E. 1995. The epidemiology of childhood hyperactivity. In: Verhulst FC, Koot $\mathrm{HH}$, eds, The Epidemiology of Child and Adolescent Psychopathology Oxford, UK: Oxford Medical Press; 178-209.

Degangi G, Porges S, Sickel R, Greenspan S. 1993. Four year follow-up of a sample of regulatory disordered infants. Infant Ment Health J 14: 330343.

Douglas VI, Parry PA. 1994. Effects of reward and non-reward on the attentional deficit of hyperactive children. J Abnorm Child Psychol 22: 281302.

Faraone S, Biederman J, Weiffenbach B, Keith T, Chu M, Weaver A, et al. 1999. Dopamine D4 gene 7-repeat allele and attention deficit hyperactivity disorder. Am J Psychiatry 156: 768-770.

Gill M, Daly G, Heron S, Hawi Z, Fitzgerald M. 1997. Confirmation of an association between attention deficit hyperactivity disorder and a dopamine transporter polymorphism. Mol Psychiatry 2: 311-313.

Goldsmith HH, Campos JJ. 1982. Towards a theory of infant temperament. In: Emde RN, Harmon RJ, eds, The Development of Attachment and Affiliative Systems. New York, NY, USA: Plenum Press; 161-193 
Goldsmith HH, Rothbart MK. 1994. The Laboratory Temperament Assessment Battery. Prelocomotor version. Madison, Wisconsin: University of Wisconsin.

Goodman R., Stevenson J. 1989. A twin study of hyperactivity II: The etiological role of genes, family relationship, and prenatal adversity. J Child Psychol Psychiatry 30: 691-709.

Greenspan S, Wieder S. 1993. Regulatory disorders. In: Zeanah $\mathrm{CH}$ Jr, ed, Handbook of Infant Mental Health. New York, NY, USA: Guildford Press; 280-290

Jacobson JJ, Fein G, Jacobson SW, Schwartz PM. 1984. Factors and clusters for the Brazelton, Scale: An investigation of the dimensions of neonatal behavior. Dev Psychol 20, 339-353.

Jacobvitz D, Sroufe A. 1987. The early caregiverchild relationship and attention deficit disorder with hyperactivity in kindergarten: A prospective study. Child Dev 58: 1496-1504.

Jeannerod M. 1994. The representing brain: Neural correlates of motor intention and imagery. Behav Brain Sci 17, 187-334.

Kinsbourne M. 1973. Minimal brain dysfunction as a neurodevelopmental lag. Ann NY Acad Sci 205: 268-273.

LaHoste G, Swanson J, Wigal S, Glabe C, Wigal T, King N, et al. 1996. Dopamine D4 receptor gene polymorphism is associated with attention deficit hyperactivity disorder. Mol Psychiatry 1: 121-124.

Levy F, Hay D, McStephen M, Wood C, Waldman I. 1997. Attention deficit hyperactivity disorder: A category or a continuum? Genetic analysis of a large-scale twin study. J Am Acad Child Adolesc Psychiatry 36: 737-744.

Mash EG, Johnson C. 1982. A comparison of the mother-child interactions of younger and older hyperactive and normal children. Child Dev 53: 1371-1381.

Melnick SM, Hinshaw SP. 2000. Emotion regulation and parenting in $\mathrm{ADHD}$ and comparison boys: Linkage with social behaviors and peer preference. J Abnorm Child Psychol 28: 73-80.

Morrell J, Murray L. 2003. Parenting and the development of conduct disorder and hyperactive symptoms in childhood: A prospective longitudinal study from 2 months to 8 years. J Child Psychol Psychiatry 44: 489-508.

Olson SL, Bates JE, Bayles K. 1990. Early antecedents of childhood impulsivity: The role of parent-child interaction, cognitive competence, and temperament. J Abnorm Child Psychol 18: 317-334.

Olson SL, Bates JE, Sandy JM, Schilling EM. 2002. Early developmental precursors of impulsive and inattentive behavior: From infancy to middle childhood. J Child Psychol Psychiatry 43: 435447.

Ramirez CA, Rosen LA, Deffenbacher JL, Hurst H, Nicoletta C, Rosencrans T, et al. 1997. Anger and anger expression in adults with high ADHD symptoms. J Atten Disord 2: 115-128.

Rende RD. 1993. Longitudinal relation between temperament traits and behavioral syndromes in middle childhood. J Am Acad Child Adolesc Psychiatry 32: 287-290.

Riese ML. 1987. Temperament stability between the neonatal period and 24 months. Dev Psychol 23: 216-222.

Rothbart M. 1981. Measurement of temperament in infancy. Child Dev 52: 569-578.

Rothbart MK. 1986. Longitudinal observation of infant temperament. Dev Psychol 22: 356-365.

Rothbart MK. 1989. Temperament in childhood: A framework. In: Kohnstamm GA, Bates JE, Rothbart MK, eds, Temperament in Childhood. New York, NY, USA: John Wiley; 59-73.

Rothbart MK, Bates JE. 1998. Temperament. In: Damon W, Eisenberg EN, eds, Handbook of Child Psychology: Social, Emotional, and Personality Development. $5^{\text {th }}$ edition, vol. 3. New York, NY, USA: Wiley; 105-176.

Ruff HA, Dubiner K. 1987. Stability of individual differences in infants' manipulation and exploration of objects. Percept Mot Skills 64, 1095-1101.

Ruff HA, Lawson KR. 1990. Development of sustained, focused attention in young children during free play. Dev Psychol 26: 85-93.

Ruff HA, Rothbart MK. 1996. Attention in Early Development. Oxford, UK: Oxford Press.

Sameroff AJ. 1978. Summary and conclusions: The future of newborn assessment. Monogr Soc Res Child Dev 43: 102-123.

Sanson A, Smart D, Prior M, Oberkland F. 1993. Precursors of hyperactivity and aggression. J Am Acad Child Adolesc Psychiatry 32: 1207-1216.

Sroufe A. 1995. Emotional Development: The Organization of Emotional Life in the Early Years. Cambridge, UK: Cambridge University Press.

Szatmari P. 1992. The epidemiology of attention- 
deficit hyperactivity disorders. Child Adolesc Psychiatr Clin N Am 1: 361-372.

Taylor E. 1999. Developmental neuropsychopathology of attention deficit and impulsiveness. Dev Psychopathol 11: 607-628.

Thomas A, Chess S, Birch HG. 1968. Temperament and Behavior Disorders in Children. New York, NY, USA: New York University Press.

Van der Meere JJ. 2002. The role of attention. In
Sandberg S, ed, Hyperactivity and Attention Disorders of Childhood. Cambridge, UK: Cambridge University Press; 162-213.

Weiss G, Hechtman LT. 1993. Hyperactive Boys Grown Up: ADHD in Children Adolescents, and Adults. New York, NY, USA: Guildford Press.

Wolke D, Rizzo P, Woods S. 2002. Persistent infant crying and hyperactivity problems in middle childhood. Pediatrics 109: 1054-1060. 

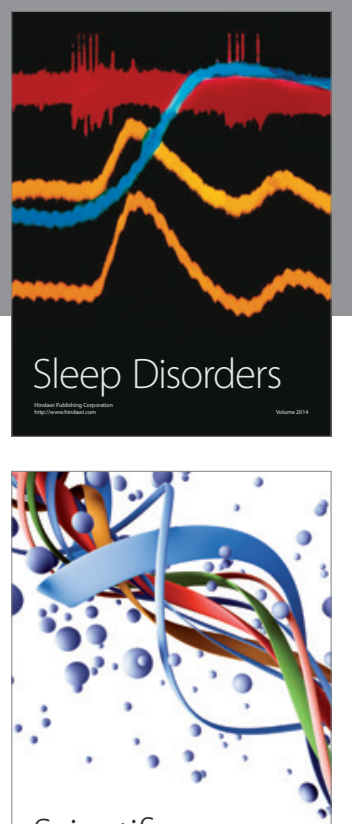

Scientifica
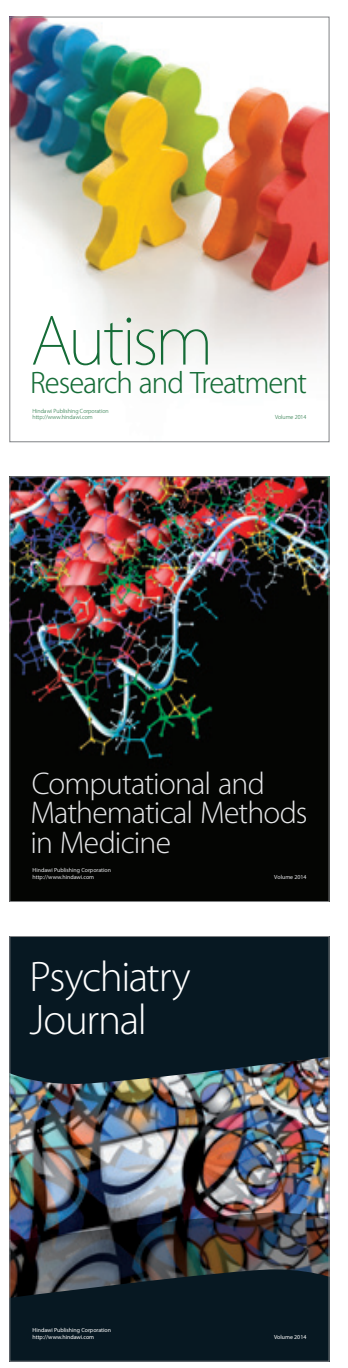
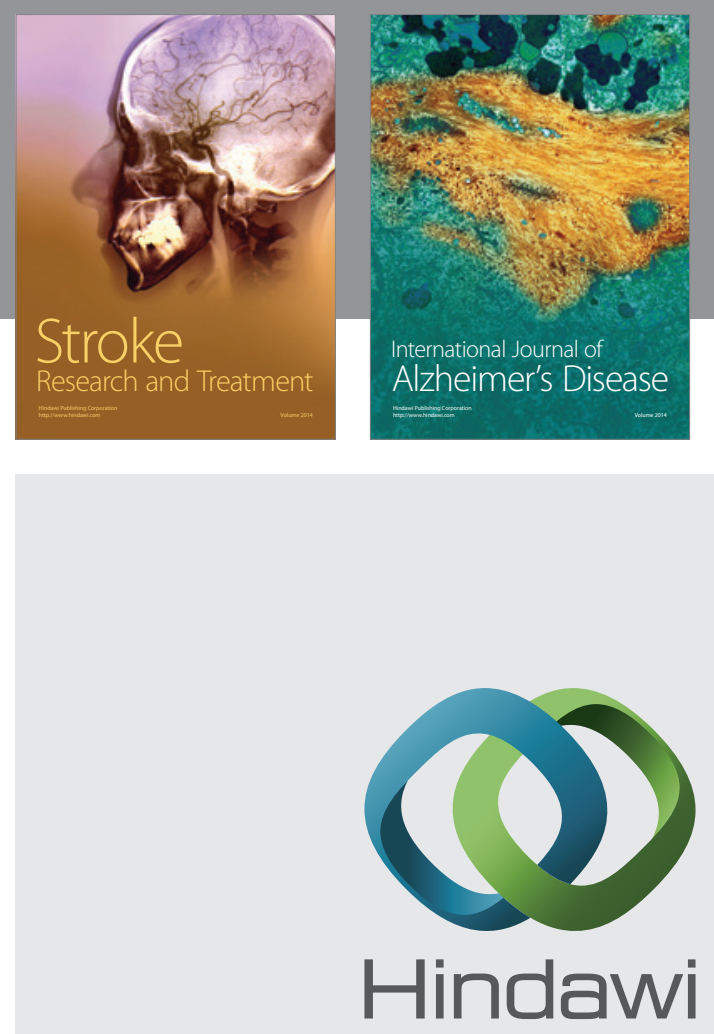

Submit your manuscripts at

http://www.hindawi.com
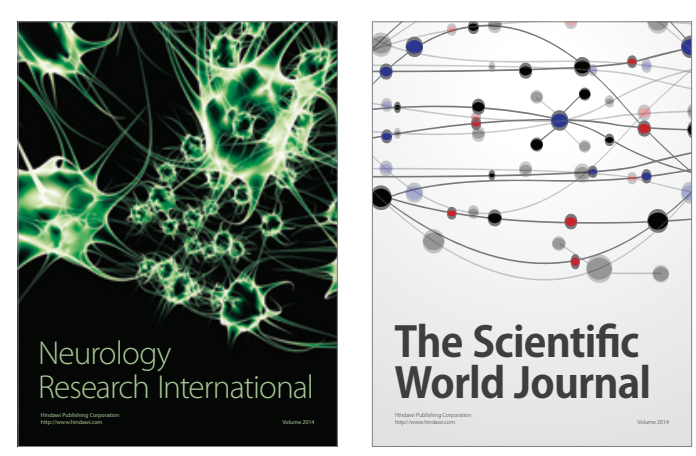

The Scientific World Journal

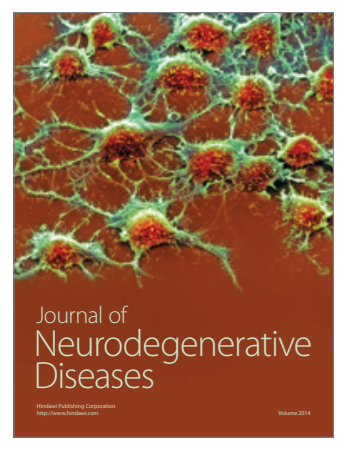

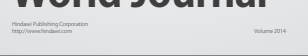

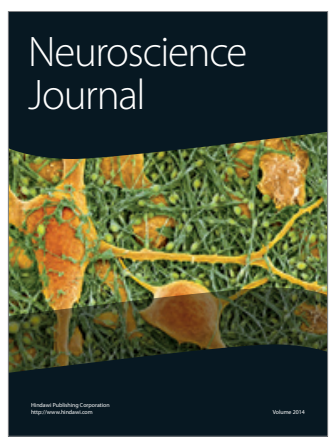

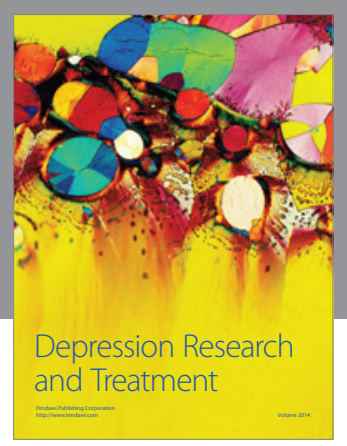
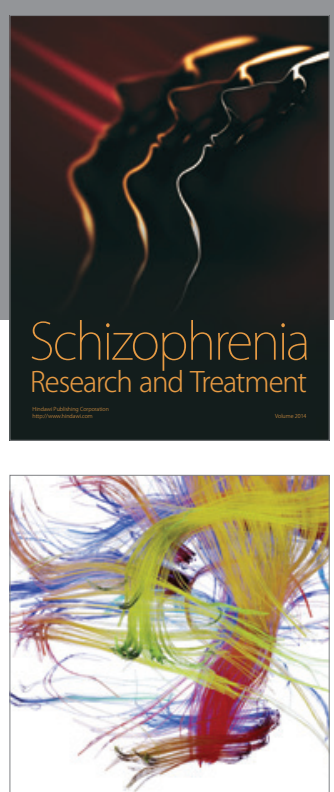

Brain Science

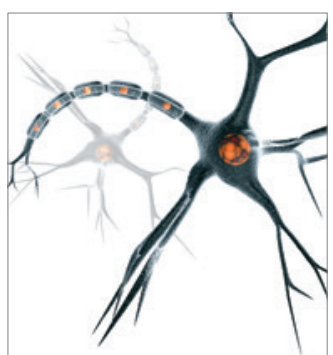

Neural Plasticity
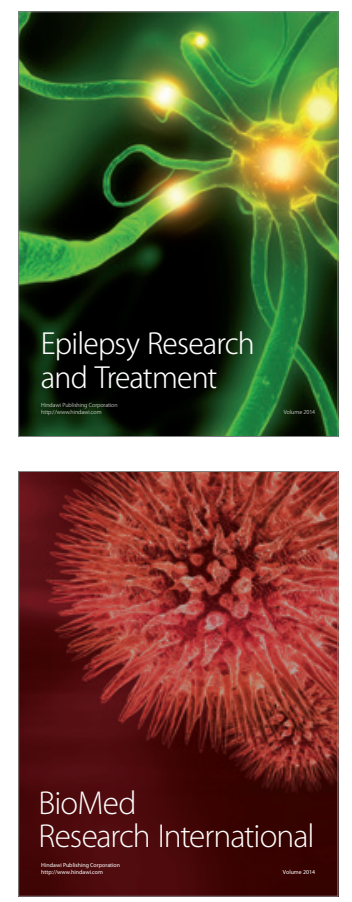

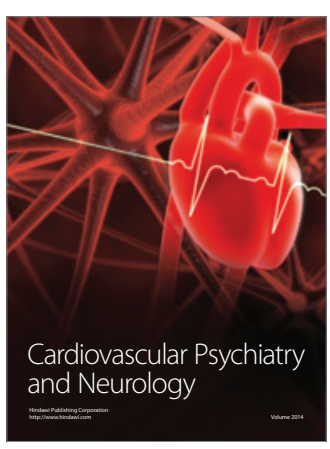

Parkinson's

Disease
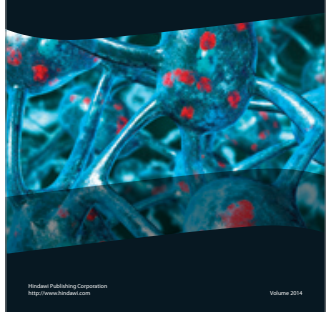